\title{
Pathogenicity of Pseudomonas morsprunorum in Relation to Host Specificity
}

\author{
By J. E. CROSSE AND CONSTANCE M. E. GARRETT \\ East Malling Research Station, Maidstone, Kent
}

(Accepted for publication 8 May 1970)

\begin{abstract}
SUMMARY
Differences in phage type between plum and cherry strains of Pseudomonas morsprunorum were stable during passage through the homologous and heterologous hosts. In experiments controlled by phage typing reisolates from lesions, both strains were specific for the homologous plant when inoculated into leaves at low concentrations $\left(<\mathrm{IO}^{5} / \mathrm{ml}\right.$.) but not at high concentrations $\left(>10^{6} / \mathrm{ml}\right.$.). No specificity was observed in wound inoculations of branches made during the winter.

Autumn inoculation of cherry leaf scars with cherry strains resulted in severe disease, with a dose response type of relationship between inoculum concentration and infection. Plum strains were ineffective through cherry leaf scars and inhibited infection by cherry strains when present in the same inoculum. The inhibitory effect was not observed with plum strains killed by heat or streptomycin, or with plum strains inoculated live in the presence of bacteriostatic levels of streptomycin.
\end{abstract}

\section{INTRODUCTION}

Pseudomonas morsprunorum Wormald causes bacterial canker disease of cultivated Prunus species and is an important factor limiting the successful cultivation of the cherry (Prunus avium) and the plum ( $P$. domestica) in Britain. It invades the stems and branches in the autumn causing extensive necrosis in the cortex and phloem. The resultant cankers are active until early the following summer, when the bacteria die in the affected tissues. Most cankers on cherry originate through leaf scars and hence are located on the branches. Cankers on plum trees usually affect the main stem, where the bacteria apparently gain access through small wounds. The pathogen survives the summer as an epiphyte on the foliage, but it may also infect the foliage, causing small necrotic leaf spots. The epidemiology of this disease is described in detail by Crosse (I966).

Plum and cherry isolates of Pseudomonas morsprunorum are indistinguishable biochemically (Garrett, Panagopoulos \& Crosse, 1966) and under certain experimental conditions they will cross-infect (Wormald, 1938). Phage typing, however, has shown them to be distinct forms with high specificity in the field for their homologous hosts (Crosse \& Garrett, 1963; Garrett \& Crosse, 1963). The experiments described below compared the pathological behaviour of plum and cherry strains through different avenues of infection and at different levels of inoculum concentration. Their object was to investigate the role of the pathological characters in determining the host distribution of these organisms. 


\section{METHODS}

Organisms. Cultures of Pseudomonas morsprunorum were isolated from necrotic leaf spots and from the leaf surfaces (Crosse, 1959) of plum and cherry trees at East Malling Research Station between 1955 and $196 \mathrm{I}$, and maintained on nutrient agar containing $2 \%$ glycerol (NGA) and stored at $4^{\circ}$.

Isolations from plant material. Necrotic tissues from the margins of advancing lesions were comminuted in sterile distilled water and the resulting suspensions plated on nutrient agar containing 5\% sucrose. On this medium Pseudomonas morsprunorum produces characteristic colonies after 3 to 4 days at $25^{\circ}$ (Crosse, 1959).

Phage typing. The media and procedures were those described by Crosse \& Garrett (1963). Typing was done with the virulent phages $\mathrm{A}_{3}, \mathrm{~A}_{7}, \mathrm{~A}_{32}$ and $\mathrm{A}_{15}$, originally from soils (Crosse \& Garrett, 1963) and with the temperate phages N5/A5 and C6/ C22 isolated from lysogenic strains of Pseudomonas morsprunorum (Garrett \& Crosse, 1963).

Preparation of inoculum. Growth from a $24 \mathrm{~h}$. slope culture on NGA was quickly suspended in $5 \mathrm{ml}$. sterile distilled water, decanted immediately into an empty sterile tube and diluted to the required concentration by reference to a calibration standard relating optical density to viable cell numbers.

Plant material. This consisted of 6- to Io-year-old field trees of the cherry cultivars Napoleon and Roundel and of the plum cultivar Victoria. A few experiments were done in the greenhouse on 3-year-old potted trees of these varieties.

Methods of inoculation. Branches were inoculated in autumn and winter through scalpel wounds in the bark and, in cherry, also through leaf scars on the fruiting spurs (I20 to I 80 spurs/treatment), by methods described by Crosse \& Garrett (I966). Leaves (20/treatment) were inoculated by spraying bacterial suspensions on the under surfaces from a hand atomizer. Immediately before inoculation leaves were sprayed with water under $15 \mathrm{lb}$./in. ${ }^{2}$ pressure until the intercellular spaces of the leaves were visibly water-congested, to aid penetration of bacteria through the stomata. In all experiments a fully replicated control treatment, with sterile water substituted for bacterial suspension, was included to estimate the level of 'background' infection from 'wild' strains of Pseudomonas morsprunorum present on the tree surfaces.

Disease assessment. The number and size of cankers from branch inoculations were recorded after 22 weeks, in May of the year following inoculation. Cankers from wound inoculations were sized by length and those from leaf scar inoculations by a rating scale ranging from $\mathrm{I}$ for a micro-canker localized in the region of a leaf scar, to Io for large cankers which killed the fruiting spur and spread more than $4 \mathrm{~cm}$. along the axis of the branch. Since many fruiting spurs were completely necrotic at the time of recording, it was impossible to determine how many of the 7 to 9 scars on each spur were initially infected. We therefore estimated this from the product

$$
\text { percentage infected spurs } \times \text { mean rating for canker size. }
$$

This procedure was justified by the fact that canker size is largely dependent on the number of scars infected (Crosse, 1957). The resultant values were termed 'the rate of leaf scar infection' and were a measure of the infectivity of the strains through the leaf scar route.

Leaf infections were recorded 10 to 24 days after inoculation as number of necrotic spots $/ \mathrm{cm} .{ }^{2}$ leaf. 


\section{RESULTS}

\section{Phage relations of the bacteria}

Phage typing. The phage types and lysogenicity of the experimental cultures are shown in Table I. Plum strains were generally distinguished from cherry strains by their insensitivity to $A_{3}$ and to the related phage A7 (Crosse \& Garrett, 1963). An exception in this instance was DI7, one of two anomalous plum isolates amongst approximately 200 examined in the course of this and previous investigations, which behaved like a cherry strain in phage typing. Cherry strains were divisible into subtypes according to their reactions to phages $\mathrm{A}_{32}, \mathrm{~A}_{15}, \mathrm{~N}_{5} / \mathrm{A}_{5}$ and $\mathrm{C} 6 / \mathrm{C}_{22}$, but the plum strains behaved uniformly with these phages and only the lysogenic strain $\mathrm{D} 2$ could be distinguished from the others on the basis of its phage relations.

\section{Table 1. Phage types of plum and cherry strains of Pseudomonas morsprunorum}

\begin{tabular}{|c|c|c|c|c|c|c|c|}
\hline \multicolumn{2}{|r|}{ Strains } & \multicolumn{6}{|c|}{ Phages (at R.T.D.) } \\
\hline \multirow{3}{*}{$\begin{array}{l}\text { Host } \\
\text { Cherry }\end{array}$} & \multirow{2}{*}{$\begin{array}{l}\text { Code no. } \\
\text { NA } 3 *, N 5^{*}, \mathrm{C} 12, \mathrm{C} 4 \mathrm{I}^{*}\end{array}$} & \multirow{2}{*}{$\begin{array}{c}\mathrm{A}_{3} \\
+\end{array}$} & \multirow{2}{*}{$\begin{array}{l}\text { A7 } \\
+\end{array}$} & \multirow{2}{*}{$\begin{array}{c}\text { A }_{32} \\
+\end{array}$} & \multirow{2}{*}{$\begin{array}{c}\text { A } 15 \\
+\end{array}$} & \multicolumn{2}{|c|}{$\mathrm{N}_{5} / \mathrm{A}_{5} \mathrm{C} 6 / \mathrm{C}_{22}$} \\
\hline & & & & & & - & + \\
\hline & $\mathrm{C} 5^{*}, \mathrm{C} 9^{*}$ & + & + & - & + & + & - \\
\hline & N7 & + & + & + & - & - & + \\
\hline & $\mathrm{C}_{17}, \mathrm{C} 22$ & + & + & + & + & + & + \\
\hline & $\mathrm{C} 46$ & + & + & + & - & + & + \\
\hline \multirow[t]{2}{*}{ Plum } & $D 17^{*}$ & + & + & + & + & - & + \\
\hline & $\left.\begin{array}{l}\text { D I, D 2,* D 4, D 5, } \\
\text { D 7, D IO, DI2, D } 18\end{array}\right\}$ & - & - & - & + & - & - \\
\hline & * Lysogenic strains. & Conf & lysis & & No rea & on. & \\
\hline
\end{tabular}

Stability of phage types during host passage. After eight successive passages through the fruitlets of each host, followed in some instances by three further passages through leaves, the phage type of each of the strains except DI2 was unchanged. This strain lost sensitivity to phage A I5 after the first passage through plum leaves and retained this character in subsequent passages. Strain DI2 has been observed to have an abnormally high rate of mutation to resistance to A 15 in vitro.

After a single passage of 22 weeks duration in plum and in cherry branch tissues, no change in sensitivity to $\mathrm{A}_{3}$ and $\mathrm{A}_{7}$ was detected in $\mathrm{I}_{4}$ of the 19 strains, but some re-isolates of $\mathrm{N} 7$ were now sensitive to phage $\mathrm{N}_{5} / \mathrm{A}_{5}$ (Table 2). Inoculations with the remaining four strains, N5, C5, D7 and D I2, yielded some re-isolates of the heterologous strain type. Since these were mostly observed in the heterologous combination, i.e. where a plum strain was inoculated to cherry and a cherry strain to plum, these re-isolates were probably homologous 'wild' strain contaminants from the plant surfaces. None of these strains was highly virulent, while three of them, N5, C 5 and DI2, were amongst the least virulent tested (Fig. I). The results of this experiment confirmed earlier work indicating that phage type was a stable and reliable marker for Pseudomonas morsprunorum in host passage experiments (Crosse \& Garrett, 1966). No changes in their lysogenicity were observed in passage experiments. 

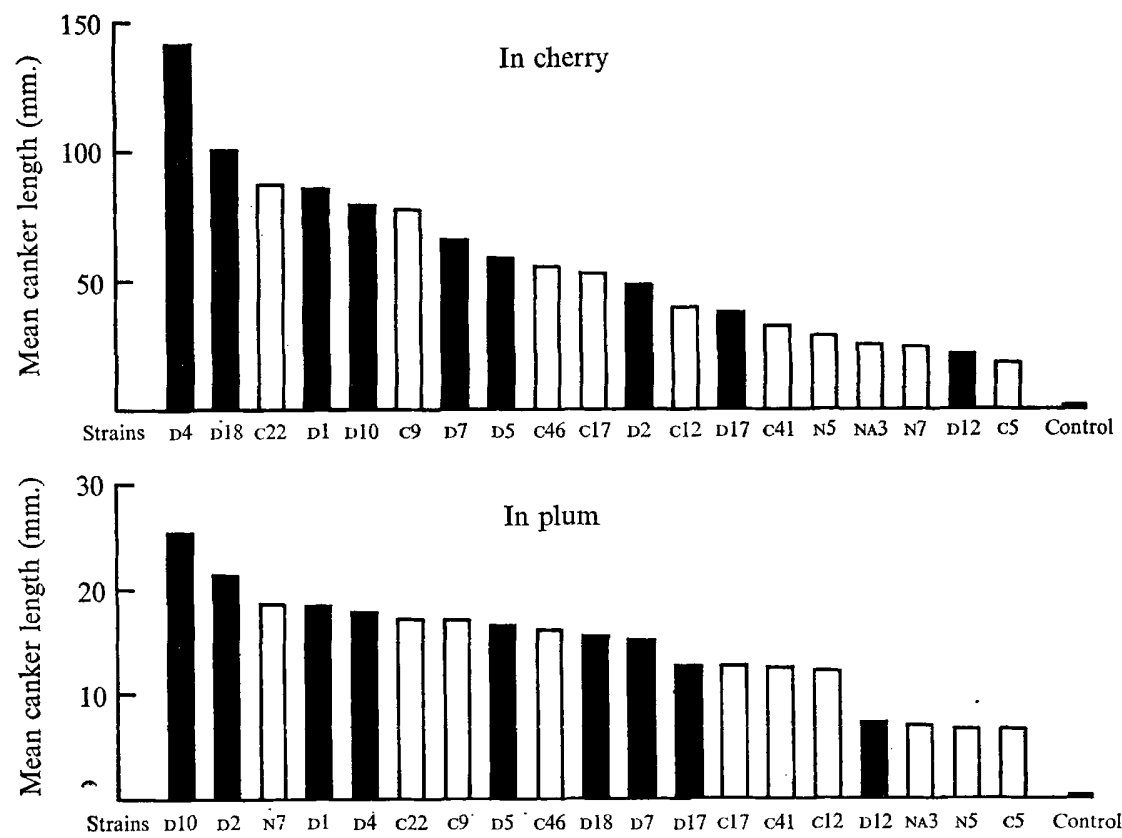

Fig. 1. Length of cankers in branches 22 weeks after inoculation through wounds during winter with individual plum strains (black columns) and cherry strains (white columns) of Pseudomonas morsprunorum (c. $10^{7}$ cells $/ \mathrm{ml}$.).

Table 2. Stability of plum and cherry phage types of Pseudomonas morsprunorum during host passage

Ten replicated inoculations of each strain were made into each host and bacteria recovered from necrotic tissues at the margins of cankers after 22 weeks. Three of the ten re-isolates in each strain +host combination were selected at random and phage typed.

No. of isolates (max. 3)

of the heterologous type

(differing from parent strain in sensitivity to phages $A_{3}$ and $A_{7}$ )

Strain

From cherry From plum

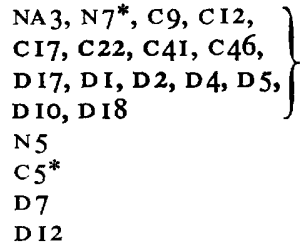

0

0

2

I

I $\quad 0$

* The majority of isolates were identical to the parent strain in all their phage reactions, but one isolate each of $\mathrm{C} 5$ and $\mathrm{N} 7$ from cherry and two of $\mathrm{N} 7$ from plum differed from the parent in sensitivity to the temperate phage $\mathrm{N}_{5} / \mathrm{A}_{5}$. 


\section{Infection experiments}

Leaf infections. The first fully expanded leaf (no. I) and the three leaves below (nos. 2 to 4 inclusive) on young growing shoots of field plum and cherry trees were inoculated through the stomata with the cherry strain $\mathrm{C} 46$ or the plum strain D ro separately and in combination. All inocula were at a concentration of $10^{4}$ cells $/ \mathrm{ml}$., giving a concentration for each strain in the combined inocula of $5 \times 10^{3}$ cells $/ \mathrm{ml}$.

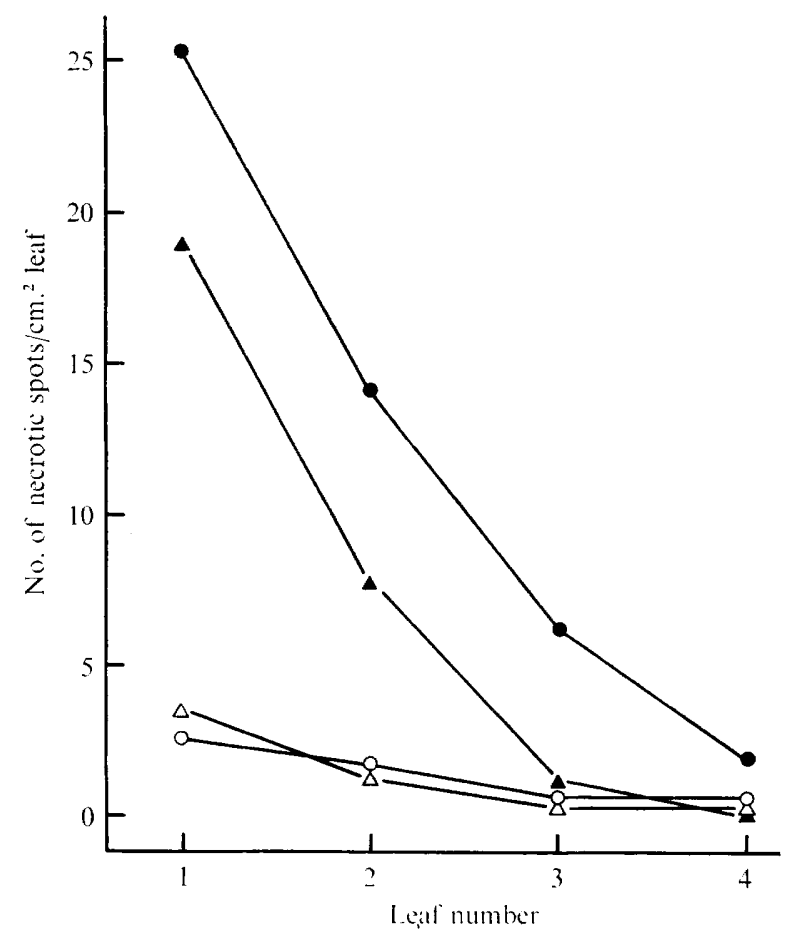

Fig. 2. Rate of leaf-spot infection by Pseudomonas morsprunorum in the first fully expanded leaf on cherry shoots (no. I) and the three successive leaves below (nos. 2 to 4 incl.). Cherry strain $\mathrm{C} 46 ; O$, plum strain D Io; $\mathbf{\Delta}, \mathrm{C} 46+\mathrm{D}$ Io; $\triangle$, control (water). Total inoculum concentration in all treatments $c .10^{4}$ cells $/ \mathrm{ml}$.

The results for cherry leaves are summarized in Fig. 2. As is common in plant diseases, the rate of infection decreased progressively down the shoot, i.e. with increasing leaf maturity. The cherry strain ( $\mathrm{C} 46)$ caused severe leaf spotting, especially on the younger leaves. The rate of infection with the heterologous plum strain (D IO) was approximately equal to that in the controls, suggesting that it was probably due to 'wild' cherry strains present on the leaf surfaces at the time of inoculation. This was subsequently confirmed by phage typing isolates from the DIO inoculations (Table 3).

Because penetration of inoculum into plum leaves was not uniform, lesions appeared as irregularly distributed patches of necrosis rather than as discrete spots. For this reason, no detailed data are shown for plum experiments, but the results were generally in line with those from cherry. Thus the homologous strain (D IO) was outstandingly the more infective, causing necrosis of more than $50 \%$ of the total lamina area in most 
inoculated leaves. The heterologous strain (C46) affected fewer leaves and never more than $25 \%$ of the lamina area. The level of infection with heterologous strain, was, however, higher than in the controls; this evidence of infection of plum by the heterologous strain was confirmed by the recovery of re-isolates exclusively of the $\mathrm{c} 46$ type from leaves inoculated with this strain (Table 3).

\section{Table 3. Incidence $(\%)$ of plum and cherry strains of Pseudomonas morsprunorum in leaf lesions}

Leaves were inoculated with $\mathrm{C} 46$ (cherry strain) and D IO (plum strain), separately and in combination. Bacteria were recovered from lesions after 10 days and from 28 to 57 isolates per treatment tested with the full range of typing phages.

\begin{tabular}{|c|c|c|c|c|}
\hline \multirow[b]{2}{*}{$\begin{array}{c}\text { Inoculation } \\
\text { treatment } \\
\left(10^{4} \text { cells } / \mathrm{ml} .\right)\end{array}$} & \multicolumn{2}{|c|}{ Cherry leaves } & \multicolumn{2}{|c|}{ Plum leaves } \\
\hline & $\begin{array}{l}\text { Cherry } \\
\text { strains }\end{array}$ & $\begin{array}{l}\text { Plum } \\
\text { strains }\end{array}$ & $\begin{array}{l}\text { Cherry } \\
\text { strains }\end{array}$ & $\begin{array}{l}\text { Plum } \\
\text { strains }\end{array}$ \\
\hline $\mathrm{C} 46$ & . & . & $100 *$ & 0 \\
\hline D IO & $98 \dagger$ & 2 & . & . \\
\hline $\mathrm{C} 46+\mathrm{D} 10$ & $100 *$ & o & $23^{*}$ & 77 \\
\hline Controls (water) & 100t & o & $12 \dagger$ & 88 \\
\hline
\end{tabular}

* Identical to $\mathrm{C} 46$ in all phage reactions except one isolate from the $\mathrm{C} 46+\mathrm{D}$ io inoculations of plum.

$\uparrow \mathrm{A}$ mixture of phage types indicating infection by 'wild' cherry strains.

The higher infectivity of $\mathrm{c} 46$ in the heterologous host showed in the results from the mixed inoculations, this strain accounting for $23 \%$ of the re-isolates from plum compared with $0 \%$ of the re-isolates of D Io from cherry. In the controls, where there was ample opportunity for cross-infection because of the very close proximity of the trees, 'wild' cherry strains were recovered from $12 \%$ of the lesions on plum leaves but no plum strains were recovered from cherry leaves. This suggests that higher infectivity in the heterologous host may be a general character of cherry strains.

The host specificity of the two strains was further examined in experiments with mixed inocula at extreme concentrations $\left(10^{2}\right.$ and $10^{7}$ to $10^{8}$ cells $/ \mathrm{ml}$.). The results showed that specificity was influenced by inoculum concentration and was only pronounced at the lower concentration (Table 4). At the higher concentration the cherry strain was predominant in both hosts and in the plum it apparently interfered with the development of homologous plum strains. In leaf infections bacteria pass through the stomata and grow initially within the confines of the substomatal vesicle. At lower inoculum concentrations there would tend to be few mixed infections of the substomatal vesicles and hence less direct interference between the strains. This probably accounts for the higher incidence of the plum strain in both hosts at the lower concentration. The unusually high incidence of the plum strain in cherry leaves inoculated with the lower inoculum concentration (Table 4) was associated with the absence of any disease symptoms. The leaves used in this experiment were fully mature, and in such leaves it seems that host specificity factors may not operate effectively, or growth of bacteria in the tissues after infection is insufficient to reveal these factors fully.

Inoculation of branches through wounds. These were made in December when plum and cherry branches tend to be most susceptible to wound infection. Each of the experimental cultures was inoculated $\left(10^{7}\right.$ cells $/ \mathrm{ml}$.) once on each of ten trees of each 


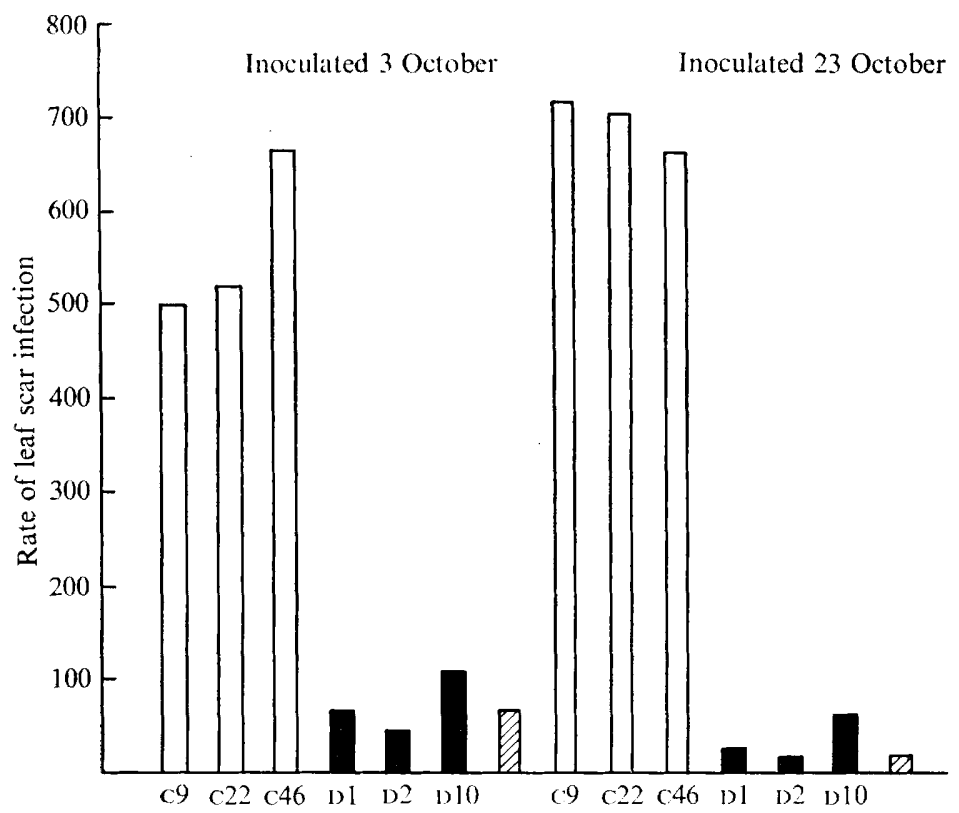

Fig. 3. Rate of cherry leaf-scar infection by individual cherry strains (white columns) and plum strains (black columns) of Pseudomonas morsprunorum on two occasions in the autumn (c. $10^{7}$ cells $/ \mathrm{ml}$.). Hatched columns denote water controls.

Table 4. Host selection of homologous strain from mixed strain inocula of Pseudomonas morsprunorum

At each inoculum concentration there were approximately equal cell numbers of $c_{4} 6$ (cherry strain) and D IO (plum strain). Bacteria were recovered from lesions II days after inoculation and approximately 100 single colony isolates from each treatment tested with phage:A 7 (C46 sensitive) and phage A 15 (D Io sensitive) to identify the strain.

\begin{tabular}{|c|c|c|c|}
\hline \multirow[b]{2}{*}{ Expt. no. } & \multirow{2}{*}{$\begin{array}{l}\text { Total inoculum } \\
\text { concentration } \\
\text { (cells } / \mathrm{ml} .)\end{array}$} & \multicolumn{2}{|c|}{$\begin{array}{l}\% \text { homologous bacteria } \\
\text { recovered from: }\end{array}$} \\
\hline & & Cherry leaves & Plum leaves \\
\hline \multirow[t]{2}{*}{ I } & $10^{8}$ & 100 & 30 \\
\hline & $10^{2}$ & 95 & 73 \\
\hline \multirow[t]{2}{*}{2} & $10^{7}$ & 98 & 5 \\
\hline & $10^{2}$ & $63^{*}$ & 100 \\
\hline
\end{tabular}

* No symptoms occurred in this treatment; bacteria were recovered from macerates of undiseased leaf tissue.

host at randomly selected sites on 2- to 3-year-old branches. The mean lengths of the cankers in the following May are shown in Fig. I. The plum and cherry strains readily cross-infected and without sign of host specificity. Among the eight strains producing the longest cankers in cherry, five were originally from plum; in plum, three of the more virulent strains were from cherry. All inoculations were successful except with the less virulent strains D I $2, \mathrm{C} 5$ and $\mathrm{N} 7$ in cherry, where 60,50 and $10 \%$ respectively of the inoculations failed. It was concluded that factors determining host specificity in plum and cherry strains did not operate effectively under these conditions of inoculation. 
Leaf scar infections of cherry fruiting spurs. Figure 3 shows the rate of leaf-scar infection with the cherry strains C9, C 22 and C46 and with the plum strains D I, D 2 and D IO, on two separate occasions in the autumn ( 3 and 23 October). At the high concentration of inoculum employed ( $10^{7}$ cells $/ \mathrm{ml}$.) each of the cherry strains induced severe disease, but the plum strains were largely ineffective (Fig. 3). Indeed, comparison with natural infection in the uninoculated controls suggested that many of the cankers recorded for the plum strains were probably due to 'wild' cherry strains. This was confirmed by phage typing bacteria from the cankers. All the isolates from the D I cankers, and $50 \%$ and $20 \%$ from the D2 and DIO cankers respectively, phage-typed as 'wild' cherry strains.

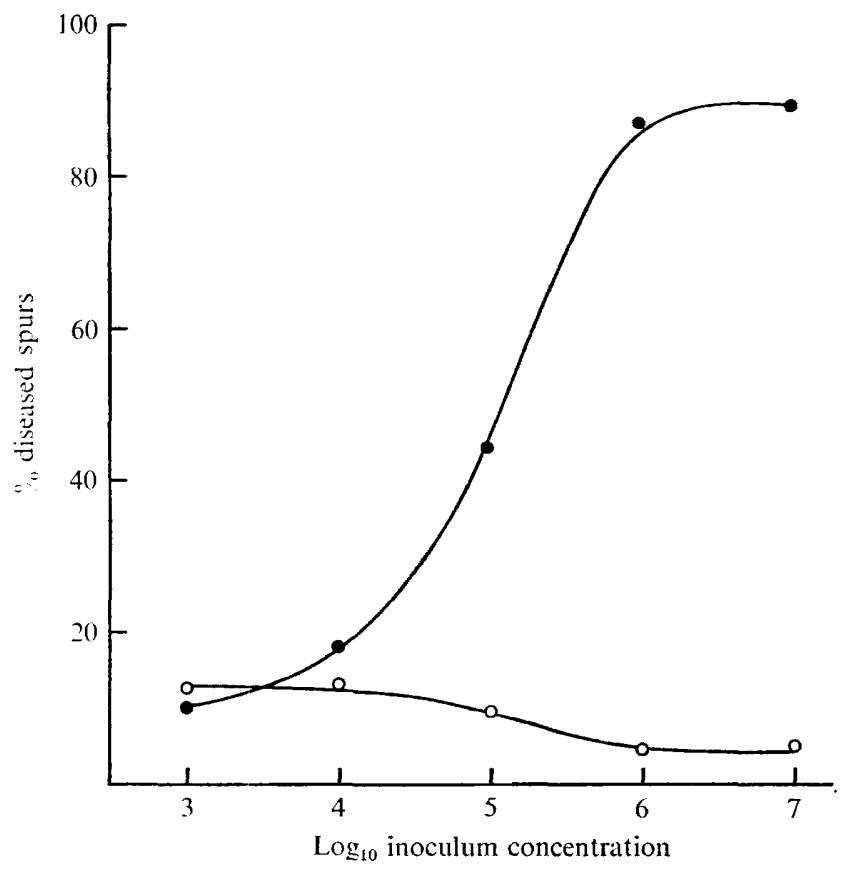

Fig. 4. Percentage diseased spurs resulting from leaf-scar infection with a mixture of five cherry strains of $P$ seudomonas morsprunorum $(\bullet)$ and with a mixture of five plum strains $(O)$ over a range of inoculum concentrations.

The next experiment compared a mixed inoculum of five cherry strains (C9, C I 2, C I 7, C 22 and C 46) with a mixed inoculum of five plum strains (D I, D 2, D 4, D 5 and D IO) over a logarithmic series of concentrations from $10^{3}$ to $10^{7}$ cells $/ \mathrm{ml}$. inclusive. The cherry strains again resulted in severe disease with a dose-response type of relationship between the log inoculum concentration and the percentage diseased spurs (Fig. 4). A few small cankers were recorded for the plum strains and these were subsequently shown by phage typing to be due to 'wild' cherry strains. There were indications that these 'wild' strain infections were inhibited at the higher inoculum concentrations of the plum strains (Fig. 4). This was supported by the data on canker size (Fig. 5). Thus with cherry strains canker size increased with the inoculum concentration, but with the plum strains it decreased. The latter anomalous result can be explained by assuming that the plum strains inhibited most readily those 'wild' strain 


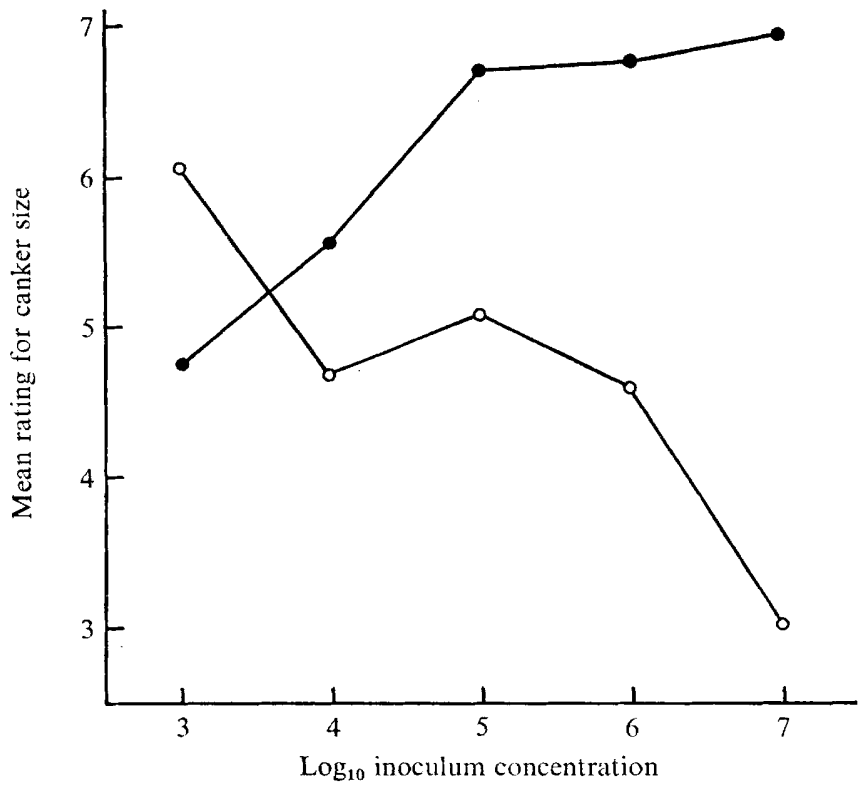

Fig. 5. Mean rating for canker size. Details otherwise as in Fig. 4.

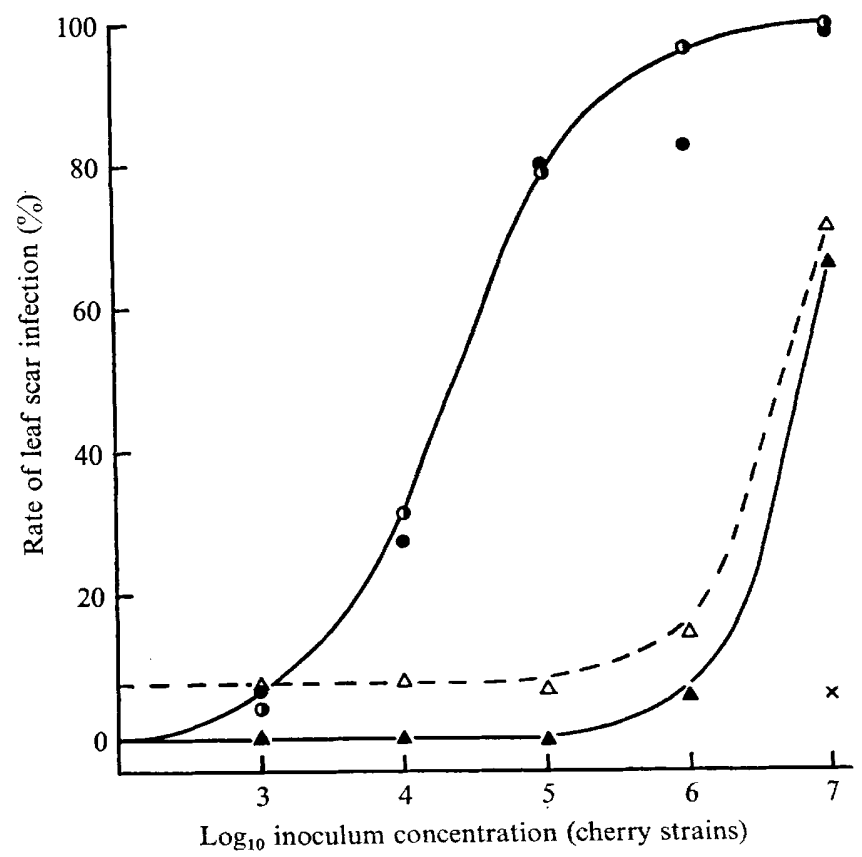

Fig. 6. Rate of cherry leaf scar infection $\% *$ with different inoculum concentrations of a mixture of five cherry strains of Pseudomonas morsprunorum in the presence and absence of a fixed concentration $\left(c .10^{7}\right.$ cells $/ \mathrm{ml}$.) of a mixture of five plum strains. ( $)$, Cherry strains alone; (A), plus live plum strains; $(\mathbf{O})$, plus heat-killed plum strains; $(\times)$, incidence of pinpoint necroses with plum strains alone; continuous lines, typical symptoms; broken line, all symptoms, including pinpoint necroses.

Corrected for natural infection, and expressed as percentage of the rate of infection at the highest inoculum concentration (see text). 
infections which would have given rise to the smallest cankers. The result would be to increase mean canker size in the successful 'wild' strain infections.

Inhibition of cherry by plum strains in leaf-scar infections on cherry. Figure $6 \mathrm{com}-$ pares the infectivity of the mixture of cherry strains over the inoculum concentration range $10^{3}$ to $10^{7}$ cells $/ \mathrm{ml}$. inclusive, in the presence and absence of a fixed concentration of $10^{7}$ cells $/ \mathrm{ml}$. of a mixture of plum strains.

The data indicated that the rate of infection with cherry strains at $10^{7}$ cells $/ \mathrm{ml}$. was the maximum possible in this experiment. All other values were therefore expressed

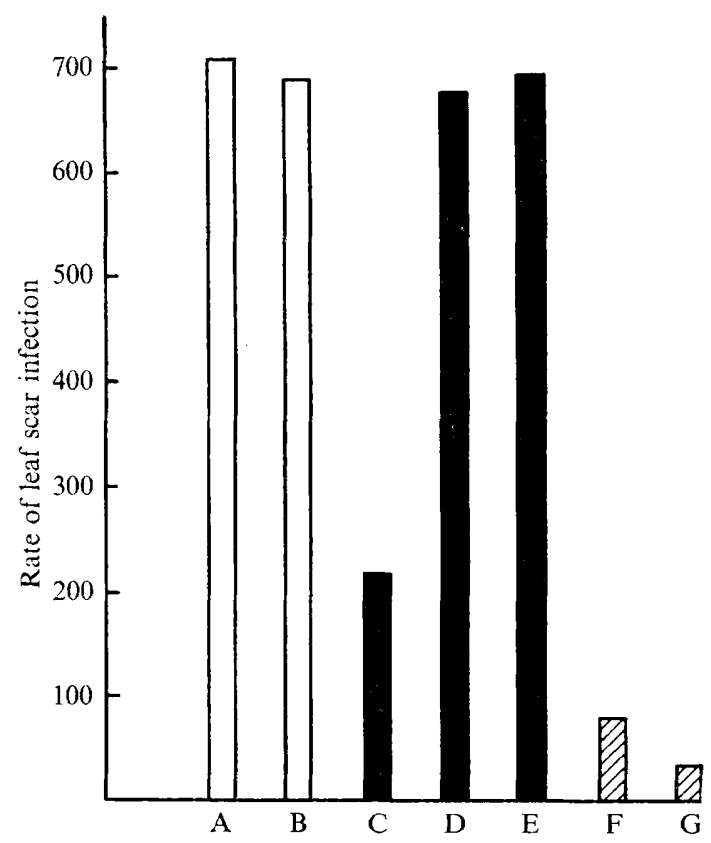

Fig. 7. Rate of leaf-scar infection with a streptomycin-resistant mutant of the cherry strain C 22 of Pseudomonas morsprunorum $\left(c, 10^{6}\right.$ cells $/ \mathrm{ml}$.) in the presence and absence of the streptomycin-sensitive plum strain, DIO (c. $10^{7}$ cells $/ \mathrm{ml}$.). A, Cherry strain alone (white columns) in water; $\mathrm{B}$, in streptomycin; $\mathrm{C}$, cherry strain plus plum strain (black columns) in water; $\mathrm{D}$, in streptomycin; $\mathrm{E}$, with plum strain killed with streptomycin. $囚$, Controls; $F$, water; $G$, streptomycin. Concentration of streptomycin in $B, D$ and $G, 0 \cdot 72$ i.u./ml.

as a percentage of this and then corrected for natural infection by the method described by Fisher \& Yates (1953). The continuous lines refer to dark brown, watersoaked lesions typical of infection by cherry strains. In the absence of plum strains the rate of infection percentage with cherry strains followed a dose-response pattern and this was not affected by the presence in the inoculum of plum strains which had been killed by heat treatment at $60^{\circ}$ for ro min. The presence of live plum strains, however, reduced infection by the cherry strains at the higher concentrations of inoculum and totally inhibited it at the lower concentrations. The inhibitory effect of the plum strains was thus proportional to their relative numbers in the inoculum.

Fruiting spurs inoculated with live plum strains in this experiment produced leaf and blossom normally in the following spring, but several spurs showed a dry pinpoint necrosis, centred around the vascular traces in one or two of the leaf scars. This 
feature was noted whenever live plum strains were present in inoculum and especially with cherry strains at the lower concentrations. The broken line in Fig. 6 refers to all infections, including pinpoint necroses. At concentrations of the cherry strains less than $10^{6} \mathrm{cell} / \mathrm{s} / \mathrm{ml}$. the incidence of infections, mostly pinpoint necroses, remained constant at a level slightly above that observed with plum strains alone. The rate at which plum strains induced pinpoint necrosis was therefore not affected by the presence of cherry strains in the inoculum.

The inhibitory activity of the plum strain D 5 against a streptomycin-resistant mutant of the cherry strain $\mathrm{C} 22$ was tested $(a)$ with bacteriostatic levels of streptomycin sulphate $(0.72 \mathrm{i} . \mathrm{u} . / \mathrm{ml}$.) in the inoculum and $(b)$ after the plum strain had been killed with streptomycin sulphate (18.0 i.u./ml. for $45 \mathrm{~min}$. followed by three washes in sterile distilled water). The effect of these treatments on the leaf-scar infectivity of mixed inocula which contained the plum and cherry strain at concentrations of $10^{7}$ and $10^{6}$ cells $/ \mathrm{ml}$. respectively are summarized in Fig. 7 . When present live in the inoculum, D 5 reduced the incidence of typical lesions caused by the cherry strain by approximately $70 \%$, but had no effect in the presence of streptomycin or after it has been killed by streptomycin. Streptomycin had no discernible effect on the infectivity of the cherry strain but reduced natural infection by 'wild' cherry strains in the control treatment.

\section{DISCUSSION}

Although indistinguishable when cross-inoculated through wounds in branches, plum and cherry strains behaved as distinct pathotypes with marked specificity for the homologous (natural) host in stomatal and leaf-scar inoculations. These results indicate that host distribution of Pseudomonas morsprunorum strains in the field is primarily determined by pathological characters. They further suggest that pathogenicity in this organism is not a simple 'all-or-none' character but a complex attribute involving more than one virulence factor. As to the nature of the factors responsible for host specificity, we can at present only speculate. The fact that specificity in stomatal inoculations was evident only at lower inoculum concentrations suggests that in leaf tissues it may be determined by factors controlling infection by these organisms from low inoculum doses. Ercolani \& Crosse (1966) reached similar conclusions from study of the effects of inoculum dose on the rate of growth of $P$. morsprunorum and related bacteria in vivo. They found the rate of growth of homologous organisms was independent of the dose. Comparable growth rates with heterologous organisms were observed only at the highest inoculum concentrations and growth was terminated early by a hypersensitivity reaction in the host.

The hypersensitivity reaction in bacterial diseases, originally described by Klement (I963), appears now to be a general response in leaves of non-host plants injected with phytopathogenic bacteria (Klement, Farkas \& Lovrekovich, I964; Klement \& Goodman, 1967 ). It is characterized by loss of water from plant cells and the rapid appearance of atypical necrotic symptoms coincident with the abrupt cessation of bacterial growth in the tissues (Klement \& Lovrekovich, I96r, 1962; Ercolani \& Crosse, I966).

There is evidence that the failure of heterologous plum strains to infect through cherry leaf scars, and their inhibitory effect on cherry strains, may have been due to a hypersensitivity reaction. The dry pinpoint necroses of the vascular leaf traces associated with the presence of plum strains in the inoculum was strongly reminiscent 
of this type of reaction. Plum strains also failed to inhibit when killed by heat or inactivated by streptomycin. Klement \& Goodman (1967) have shown that phytopathogenic bacteria so treated are unable to induce the hypersensitivity response in leaf tissues.

There have been several reports of bacteria, either saprophytic forms (Teliz-Oritz \& Burkholder, 1960; Crosse, I965; Goodman, 1965) or avirulent strains of pathogens (Averre \& Kelman, 1964; Goodman, 1967; Lippincott \& Lippincott, 1969), inhibiting plant infection by phytopathogenic bacteria. Averre \& Kelman (1964) attributed the inhibition of virulent by avirulent strains of Pseudomonas solanacearum to the hypersensitivity re action. As in our experiments, the inhibitory strain wasmost effective when present in the inoculum in high numbers relative to the infecting strain. Lippincott \& Lippincott (I969) found, however, that the inhibitory effect of an avirulent on a virulent strain of Agrobacterium tumefaciens was a function of the absolute concentration of the strains in the inoculum and not of their relative numbers. They concluded from this and other evidence that inhibition was due to exclusion of the virulent strain from specific attachment sites within the host tissues. The fact that the inhibitor strains in their experiments were equally effective after heat treatment is also evidence that a hypersensitivity reaction was not involved.

Why plum and cherry strains of Pseudomonas morsprunorum should infect nonspecifically through wounds in branches is not clear. These inoculations differed from leaf-scar inoculations in three major respects. The effective inoculum dose was probably massive compared with that in leaf-scar infections (Crosse, 1966); the inoculations resulted in mechanical damage to tissues at the site of infection; and they were made at a time (December) when branch tissues were fully dormant and in their most susceptible condition (Shanmuganathan, I962). It is possible that a hypersensitivity reaction was induced by heterologous bacteria in wound inoculations but was not effective against them at the very high inoculum doses employed. Alternatively, the effects of this reaction may have been neutralized by some artefact resulting from damage to the plant tissues, but it would then be difficult to explain how heterologous bacteria were able subsequently to invade the undamaged tissues. Finally, it is possible that in fully dormant tissues heterologous bacteria behave as homologous bacteria, i.e. they do not induce a hypersensitivity reaction or any other form of host defensive response.

These experiments confirm that there is a correlation between virulence characters and phage sensitivity in Pseudomonas morsprunorum, similar to that reported by Williams (1962) for staphylococci. Thus only strains sensitive to $A_{7}$ and related phages are able to infect through cherry leaf scars. We have found no exceptions to this amongst English isolates and very few amongst isolates from other countries. The plum isolate DI7, for example, which phage-typed as a cherry strain, has behaved exactly as a cherry strain in leaf-scar inoculations. In recent experiments cherry strain mutants resistant to phage $\mathrm{A}_{7}$ were found to have lost infectivity through leaf scars, suggesting that virulence factors and phage sensitivity may be linked as they are in Salmonella typhi (Craigie \& Yen, 1938). There is no proof of this, however, and the differences in phage type between plum and cherry strains of $P$. morsprunorum may simply reflect a different history of phage infection in the field. Cherry strains may have failed to acquire resistance to $A_{7}$ and related phages because these are absent from cherry, or their activity is in some way inhibited. 


\section{REFERENCES}

Averre, C. W. \& Kelman, A. (1964). Severity of bacterial wilt as influenced by ratio of virulent to avirulent cells of Pseudomonas solanacearum in inoculum. Phytopathology 54, 779-783.

Craigie, J. \& YEN, C. H. (1938). The demonstration of types of $B$. typhosus by means of preparations of type II Vi phage (1). Canadian Public Health Journal 29, 448-631.

Crosse, J. E. (I957). Bacterial canker of stone-fruits. III. Inoculum concentration and time of inoculation in relation to leaf-scar infection of cherry. Annals of Applied Biology 45, 19-35.

Crosse, J. E. (1959). Bacterial canker of stone-fruits. IV. Investigation of a method for measuring the inoculum potential of cherry trees. Annals of Applied Biology 47, 306-317.

Crosse, J. E. (1965). Bacterial canker of stone-fruits. VI. Inhibition of leaf-scar infection of cherry by a saprophytic bacterium from the leaf surfaces. Annals of Applied Biology 56, 149-160.

Crosse, J. E. (1966). Epidemiological relations of the pseudomonad pathogens of deciduous fruit trees. Annual Review of Phytopathology 4, 291-310.

Crosse, J. E. \& GarretT, C. M. E. (1963). Studies on the bacteriophagy of Pseudomonas morsprunorum, Ps. syringae and related organisms. Journal of Applied Bacteriology 26, I 59-177.

Crosse, J. E. \& GarretT, C. M. E. (I966). Bacterial canker of stone-fruits. VII. Infection experiments with Pseudomonas morsprunorum and P. syringae. Annals of Applied Biology 58, 31-4I.

Ercolani, G. L. \& Crosse, J. E. (1966). The growth of Pseudomonas phaseolicola and related plant pathogens in vivo. Journal of General Microbiology 45, 429-439.

Fisher, R. A. \& YATES, F. (1953). Statistical Tables for Biological, Agricultural and Medical Research. Edinburgh: Oliver \& Boyd.

Garrett, C. M. E. \& Crosse, J. E. (1963). Observations on lysogeny in the plant pathogens Pseudomonas morsprunorum and Ps. syringae. Journal of Applied Bacteriology 26, 27-34.

Garrett, C. M. E., Panagopoulos, C. G. \& Crosse, J. E. (I966). Comparison of plant pathogenic pseudomonads from fruit trees. Journal of Applied Bacteriology 29, 342-356.

Goodman, R. N. (1965). In vitro and in vivo interactions between components of mixed bacterial cultures isolated from apple buds. Phytopathology 55, 2I 7-22I.

Goodman, R. N. (1967). Protection of apple stem tissue against Erwinia amylovora infection by avirulent strains and three other bacterial species. Phytopathology 57, 22-24.

KLEMENT, Z. (1963). Rapid detection of the pathogenicity of phytopathogenic pseudomonads. Nature, London 199, 299-300.

Klement, Z., Farkas, G. L. \& Lovrekovich, L. (I964). Hypersensitive reaction induced by phytopathogenic bacteria in the tobacco leaf. Phytopathology 54, 474-477.

Klement, Z. \& Goodman, R. N. (1967). The hypersensitive reaction to infection by bacterial plant pathogens. Annual Review of Phytopathology 5, 17-44.

Klement, Z. \& Lovrekovich, L. (196I). Defence reactions induced by phytopathogenic bacteria in bean pods. Phytopathologische Zeitschrift 4I, 21 7-227.

KLEment, Z. \& Lovrekovich, L. (I962). Studies on host-parasite relations in bean pods infected with bacteria. Phytopathologische Zeitschrift 45, 8I-88.

LipPINCOTT, B. B. \& LipPINCOTT, J. A. (1969). Bacterial attachment to a specific wound site as an essential stage in tumor initiation by Agrobacterium tumefaciens. Journal of Bacteriology 97, $620-628$.

Shanmuganathan, N. (1962). Studies in Bacterial Canker of Plum and Cherry (Pseudomonas morsprunorum Wormald). Ph.D. thesis, University of London.

Teliz-Oritz, M. \& Burkholder, W. H. (1960). A strain of Pseudomonas fluorescens antagonistic to Pseudomonas phaseolicola and other bacterial plant pathogens. Phytopathology 50, I I9-I 23.

Williams, R. E. O. (I962). Ecological evidence for the existence of virulent strains of staphylococci. In Proceedings of the VIIIth International Congress for Microbiology, Toronto, p. 55 I. Toronto, Canada: University of Toronto Press.

Wormald, H. (1938). Bacterial diseases of stone fruit trees in Britain. VII. The organisms causing diseases in sweet cherries. Journal of Pomology 16, 280-290. 